\title{
The Index of Function Suitability (IFS): A new tool for assessing the capacity of landscapes to provide amenity functions
}

\author{
Teresa Pinto-Correia ${ }^{\mathrm{a}, *}$, Sónia Carvalho-Ribeiro ${ }^{\mathrm{b}}$ \\ a ICAAM - Institute for Mediterranean Agrarian and Environmental Sciences, Mediterranean Ecosystems and Landscapes (MEL) Research group, \\ DPAO - Department Landscape Environment and Planning, University of Évora, Núcleo da Mitra, Apartado 94, 7002-774 Évora, Portugal \\ ${ }^{\mathrm{b}}$ Institute for Mediterranean Agrarian and Environmental Sciences, Mediterranean Ecosystems and Landscapes (MEL) Research Group, University of Évora, \\ Núcleo da Mitra, Apartado 94, 7002-774 Évora, Portugal
}

\section{A R T I C L E I N F O}

Article history:

Received 11 October 2010

Received in revised form 10 May 2011

Accepted 10 May 2011

\section{Keywords:}

Index of Function Suitability

Integrated landscape management

Social demands

Amenity functions

Indicators

User based preferences

\begin{abstract}
A B S T R A C T
Integrating social demands into landscape management has been proven difficult because of a lack of suitable measures. In order to address this issue this article describes the development of the Index of Function Suitability (IFS). This offers an integrated conceptual tool for incorporating social demands into landscape management. The IFS links preferences to land cover spatial patterns as it uses quantitative indicators for gauging differences between the preferred landscape patterns by users, for a certain activity related to an amenity function (e.g. hunting), and the land cover patterns of a given rural area (either at the present or from scenarios developed for the future). Introducing the measurement of the difference between the preferred spatial patterns and the landscape patterns occurring in a given landscape is a fundamental conceptual development represented in the IFS. By using the same set of indicators to quantify different land cover patterns, the IFS gauges quantitatively the differences between their spatial patterns, thus providing landscape managers with an indication of the suitability of changing land covers to support the selected amenity functions. In this paper, the conceptual aspects, as well as the methodological steps of the IFS were explained and further applied to one empirical case study in the Alentejo region of Portugal. This paper also examines both the strengths and weaknesses of the IFS approach along with a discussion for improvement.
\end{abstract}

(C) 2011 Elsevier Ltd. All rights reserved.

\section{Introduction}

Across Europe, the social demand for amenity in rural landscapes have been steadily increasing (Dissart and Vollet, 2011; Sayadi et al., 2009; Sevenant and Antrop, 2010; Terwan et al., 2004). Amenity functions are introduced here as relating to information (de Groot et al., 2002) or cultural functions (MEA, 2005) namely aesthetic, recreation and cultural dimensions, supporting activities such as walking, cycling, bird watching and hunting.

Agriculture is no longer seen as only a way to convert land into productive goods. Instead, agriculture is regarded as an integral part of a set of activities shaping the landscape, which in turn, forms the basis for more varied land cover development on a multifunctional basis. This requires new management approaches, ranging from productivism to amenity linked post-productivism (Tilzey and Potter, 2008; Wilson, 2007). Those amenity functions reflect the preferences of users such as tourists, hunters, bird watchers, locals, new-rural dwellers, visitors, second house owners

\footnotetext{
* Corresponding author. Tel.: +351 266740800x4563; fax: +351266 760913.

E-mail addresses: mtpc@uevora.pt (T. Pinto-Correia), sribeiro@uevora.pt (S. Carvalho-Ribeiro).
}

(Natori and Chenoweth, 2008; Stephenson, 2008; Surova and PintoCorreia, 2008). The ability of a landscape to provide these functions can be thus measured in relation to user based preferences.

A literature review on landscape preferences by different user groups, indicates that preferences are likely to vary with personal and socio-economic factors such as gender and landownership (Abello and Bernaldez, 1986; Tips and Vasdisara, 1986), professional background (Natori and Chenoweth, 2008; Rogge et al., 2007; Winter, 2005), but mainly with type of recreational activity (Harshaw et al., 2006; Roovers et al., 2002; Sheppard et al., 2001; Tahvanainen et al., 2001). Therefore, the work developed throughout this article focuses on user based preferences for different land cover patterns assessing the ways in which a certain user "likes" one land cover pattern better than another for a specific amenity activity (Swanwick, 2009).

It is acknowledged that individuals might have distinct preferences according to whether they adopt a user/consumer or a citizen viewpoint (van Rensburg et al., 2002). For example, a livestock grazer may find a dense and contiguous forest aesthetically pleasing, while acknowledging that his/her own livestock will not be able to thrive in such habitat (Ribe, 2002). Similarly, Tahvanainen et al. (2001) suggests that clear cut might be appreciated by someone picking berries even though the scenic beauty is likely to be 